\title{
FRONTEIRAS ENTRE DUAS ESFERAS DAS ATIVIDADES SOCIAIS: A EDUCAÇÃO E O TRABALHO
}

\author{
APARECIDA NERI DE SOUZA*
}

\begin{abstract}
A sociologia não é um discurso, não é uma retórica, não é um ensaísmo: é um trabalho de pesquisa, de comprometimento com a realidade.
\end{abstract}

(Florestan Fernandes, 1960)

\begin{abstract}
RESUMO: Como construir análises de determinadas dimensões da realidade social que são tratadas, geralmente, de maneira separada, ora pela sociologia da educação, ora pela sociologia do trabalho? Para responder a esta questão a obra de Lucie Tanguy é examinada. Ao propor a análise crítica sobre um campo de conhecimento que é objeto de debate e de discursos programáticos, é possível relevar as tensões nas quais a educação profissional é objeto. De forma geral, a educação profissional, seja aquela destinada à formação de operários, seja aquela destinada à formação de técnicos, é desconhecida dos sociólogos que estudam a educação escolar. A análise permite romper com certos mitos sobre a formação profissional, entre os quais aqueles que representam a educação como instrumento de reprodução social.
\end{abstract}

Palavras-chave: Lucie Tanguy. Sociologia. Educação e trabalho. Sociologia da educação. Sociologia do trabalho.

\section{THE BORDERS BETWEEN TWO SPHERES OF SOCIAL ACTIVITIES:} EDUCATION AND WORK

ABSTRACT: How can we draw up analysis of certain social reality dimensions which are generally treated, separately, either by the sociology of education and by the labor sociology? To answer this question, the work by Lucie Tanguy is examined. By proposing a critical analysis of a field of knowledge which is the object of debates and action plan speeches it is possible to overlook the tensions in which the professional education is the object. In general, professional education, either the one targeted to the formation of blue collar workers or the one targeted to the formation of technicians, is not known by

\footnotetext{
* $\quad$ Doutora em Educação e professora da Faculdade de Educação da Universidade Estadual de Cam-
} pinas (Unicamp). E-mail: anerisouza@uol.com.br 
the sociologists who study school education. The analysis allows us to break down certain myths about professional formation, among them the ones that refer to education as an instrument of social reproduction.

Key words: Lucie Tanguy. Sociology. Education and work. Sociology of education. Labor sociology.

\section{FroNTIÈRES ENTRE DEUX SPHÈRES DES ACTIVITÉS SOCIALES: L'ÉDUCATION ET LE TRAVAIL}

RÉSUMÉ: Comment construire les analyses de certaines dimensions de la réalité sociale qui sont traitées, généralement, de manière séparée, soit par la sociologie de l'éducation, soit par la sociologie du travail? Pour répondre à cette question l'oeuvre de Lucie Tanguy est examinée. La proposition d'une analyse critique sur un champ de connaissance, qui est l'objet de débats et de discours programmatiques, permet de relever les tensions liées à l'éducation professionnelle. Souvent, l'éducation professionnelle, aussi bien celle destinée à la formation d'ouvriers, que celle destinée à la formation de techniciens, est méconnue par les sociologues qui étudient l'éducation scolaire. L'analyse permet de briser certains mythes sur la formation professionnelle, dont ceux qui représentent l'éducation comme instrument de reproduction sociale.

Mots-clés: Lucie Tanguy. Sociologie. Éducation et travail. Sociologie de l'éducation. Sociologie du travail.

\section{Introdução}

$\mathrm{E}$

ste texto, ao analisar as relações entre educação e trabalho, interroga sobre a contribuição de Lucie Tanguy não só para a formação de sociólogos, como também para a singularidade de seu percurso na Sociologia que tem como objeto de estudos e pesquisas a educação e o trabalho. A sociologia de Lucie Tanguy encontra-se com Florestan Fernandes na recusa, de ambos, de que há "sociologias especiais".

Como acontece com qualquer ciência, os métodos sociológicos podem ser aplicados à investigação e à explicação de qualquer fenômeno social particular sem que, por isso, se deva admitir a existência de uma disciplina especial, com objeto e problemas próprios! Essa tendência teve razão de ser no passado, enquanto pairavam dúvidas sobre as questões essenciais, relativas ao objeto da Sociologia, à natureza da explicação sociológica e às técnicas de investigação, recomendáveis no estudo sociológico dos fenômenos sociais. (Fernandes, 1960, p. 29-30)

As formas e modos de apresentação da Sociologia decomposta por domínios de especialização são recursos mais heurísticos que científicos. Há uma originalidade sociológica quanto ao método e teorias que a diferenciam de outros campos de conhecimento científico. A Sociologia não é reinventada pela sua diversidade de temas - educação, trabalho, profissões, religiões, família, entre outros -, mas ela é 
recriada nos métodos, problemáticas e teorias. O fato de que a produção de estudos e pesquisas sobre uma determinada temática pode conduzir, inevitavelmente, a um processo de especialização ou domínio de uma vasta literatura sobre o mesmo tema, não se confunde com a divisão da Sociologia pelos seus objetos, pois não há teorias sociológicas específicas para temáticas particulares. Assim, a constituição de especialidades, as definições e fronteiras são histórica e socialmente construídas.

Tomando um conjunto de textos selecionados da socióloga francesa Lucie Tanguy e aceitando a proposição desta autora de que as análises de determinadas dimensões da realidade social, a exemplo do trabalho e da educação, não podem ser tratadas de forma dicotômica, este artigo se propõe a compreender as possibilidades analíticas da sociologia que interroga a própria sociologia. A seleção dos textos de Tanguy ganha sentido se associada ao tema proposto, ou seja, às fronteiras (ou às ausências destas) entre educação e trabalho. De forma geral, trata-se de estudos sobre duas atividades sociais - educação e trabalho - no âmbito de um país capitalista central, numa perspectiva sócio-histórica que tem como recorte temporal o pós-guerra. Se, por vezes, o texto apresenta comparações entre Brasil e França, elas devem ser lidas com os cuidados de salvaguardar as singularidades das duas formações nacionais. Ressalto também a particularidade da produção sociológica de Tanguy, herdeira de uma tradição intelectual e de modos de pesquisar que privilegiam não somente as pesquisas empíricas, mas também, e sobretudo, o diálogo realizado com fina vigilância epistemológica entre a sociologia e a história. Os textos selecionados, pelas chaves teóricas e metodológicas apresentadas, nos permitem construir categorias sociológicas como referências analíticas comuns. Neste artigo serão destacadas as noções de educação, formação, qualificação e competências.

Metodologicamente, Tanguy busca superar a correspondência entre a objetividade das estruturas e as posições e disposições dos sujeitos de conhecimento nas análises que realiza sobre as modalidades de percepção e de conhecimento dos fenômenos e grupos sociais. É nesta direção que sua análise sobre as transformações sociais apreende elementos de indeterminação e incertezas nas relações entre experiências e posições sociais, rejeitando assim, metodologicamente, a tentação às generalizações sociológicas. A análise sociológica deve se integrar na dimensão temporal, histórica, para reconstruir as relações entre os fenômenos diferentes, seja o econômico, técnico, trabalho ou a educação, que se movimentam em ritmos próprios. Ignorar o passado não afeta apenas o conhecimento do presente, mas compromete, no presente, a ação em si, nos informa Tanguy, em concordância com Marc Bloch.

Neste sentido, esse modo de fazer sociologia permite não só rejeitar a concepção de que a educação técnico-profissional possa ser compreendida em termos de atrasos ou de inadequações sociais e econômicas de diferentes grupos sociais (concepções caras às teorias da reprodução cultural e social); mas também possibilita 
rejeitar a concepção de que crise social se confunde com tensões ou conflitos sociais. A análise produzida por Tanguy permite romper com certos mitos sobre a formação profissional, entre os quais aqueles que representam a educação como instrumento de reprodução social, entendida, por vezes, como um movimento de adaptação dos homens e mulheres às mudanças tecnológicas, ou ainda como um instrumento de democratização das relações sociais na empresa e na sociedade. Há que interrogar, nesta perspectiva, o sentido das palavras e noções que escondem as tramas e conflitos sociais em torno das fronteiras entre educação e trabalho.

O ponto de partida da análise aqui proposta é a pesquisa publicada no livro L'enseignement professionnel em France - des ouvriers aux techniciens. ${ }^{1} \mathrm{Na}$ introdução a autora afirma que sua pesquisa apresentada está localizada numa fronteira entre as esferas do trabalho e da educação.

\begin{abstract}
Para construir e analisar um tal objeto, é necessário alcançar e colocar em evidência as dimensões da realidade social que são geralmente tratadas de maneira separada pela sociologia da educação, de uma parte, e pela sociologia do trabalho de outra parte. Esta construção é ainda mais difícil de ser realizada, pois o ensino técnico é "um campo (um pouco) abandonado" por este tipo de homologia já salientada pela pesquisa e seus objetos: abandonada pelos historiadores (...) e igualmente pouco abordado pelos sociólogos. (Tanguy, 1991, p. 13; tradução da autora)
\end{abstract}

Ao propor a análise crítica sobre um campo de conhecimento que é objeto de debate e de discursos programáticos e pragmáticos, é possível revelar as tensões nas quais a educação profissional é objeto. De forma geral, a educação profissional, seja aquela destinada à formação de operários, seja aquela destinada à formação de técnicos, é pouco conhecida dos sociólogos que estudam a educação e ou o trabalho.

A abordagem adotada por Tanguy se difere sensivelmente daquela que privilegia os estudos das instituições ou das políticas, tal como encontramos na maioria dos estudos sobre a educação profissional, tanto no Brasil como na França. Nesse sentido, ela se propõe a produzir menos uma sociologia das instituições de ensino profissional e mais uma sociologia histórica sobre uma atividade social - a educação - que parece não cessar de se autonomizar em relação às outras esferas de atividades sociais.

Tanto no Brasil como na França observa-se um apelo generalizado à educação e à formação profissional para realizar e levar a bom termo as mudanças no mercado e nos processos de trabalho. Frequentemente, a educação é compreendida como um remédio milagroso para resolver os problemas do mercado de trabalho e de adaptação ao posto de trabalho. As últimas quatro décadas são marcadas por transformações consideráveis no mundo do trabalho. Mundialização ou globalização, competição, crise econômica e desemprego; transformação do trabalho em relação às novas 
tecnologias de informação e comunicação; generalização das atividades de serviço; questionamento das formas taylorizadas de organização do trabalho; individualização das situações de trabalho e de gestão dos trabalhadores colocam em evidência as capacidades de adaptação destes. As competências que determinam a empregabilidade e o questionamento do papel da educação são evidências deste movimento que parece autonomizar a esfera da educação se comparada com as demais esferas.

\section{Distinção entre educação e formação}

Lucie Tanguy também distingue as noções de educação e de formação. A noção de formação é compreendida como uma atividade social de transmissão e aquisição de conhecimentos, comportamentos e atitudes. Não mais reservada à instituição escolar, ela é associada à formação da força de trabalho.

\footnotetext{
Seria possível mostrar que a noção de formação foi construída por diferença e em oposição à noção de educação (...). A noção de formação enraíza-se muito mais nas mudanças a promover na esfera econômica e profissional, enquanto a educação sustenta-se na evolução das diferenças das formas de vida do indivíduo (Tanguy, 2002, p. 20)
}

Na França, a educação aparece estreitamente vinculada à forma escolar. No Brasil, as duas noções aparecem como sinônimos, daí a necessidade de expor esta distinção. Nesta direção é necessário ao pesquisador interrogar os sentidos das noções e dos processos de nomeação. Afinal, nos pergunta Tanguy, o que está na base dos problemas sociais que as sociedades contemporâneas conhecem e como estes problemas são nomeados historicamente?

A formação é uma categoria social irredutível a outras modalidades educativas pelos objetivos que lhe são atribuídos. A formação, na França, foi definida e implementada como parte de reformas econômicas, políticas e sociais realizadas após a Segunda Guerra Mundial, uma noção associada ao processo de modernização do país. Como vetor de mudanças econômicas e sociais, a noção foi construída em oposição à noção de educação, pois esta última refere-se "às diferentes formas de vida de um indivíduo" e a primeira à promoção da esfera profissional. A formação, definida pelos seus objetivos, é compreendida como um instrumento de mudanças das relações de trabalho nas empresas. E, nesta direção, é colocada como condição para acesso ao emprego. Portanto, estabelece-se uma relação de equivalência entre formação e emprego.

Ao colocar em prática sua concepção de pesquisa sociológica, como atividade social, Tanguy indaga não somente sobre o contexto social e político em que emerge, não só, esta noção de formação, assim como as relações improváveis entre formação 
e emprego; também interroga quem são os atores que impulsionam esta concepção de formação e como constroem os consensos. Assim,

(...) a vontade de promover a formação como fator de produtividade, de inovação social, de mobilidade, cedeu lugar (...) [ao estudo dos] obstáculos à ideia de formação e os empecilhos à sua realização. (...) Operação que exige elaborar uma definição consensual da formação. (Idem, ibid., p. 26).

Daí a tendência de conferir à formação a representação de um bem comum e universal. As ações de formação são apresentadas como responsáveis pela adaptação da força de trabalho às mudanças técnicas, pelo aumento da produtividade e dinamização da economia, pelo enfrentamento do desemprego e manutenção da coesão social. Colocar em xeque as relações entre formação e emprego impõe, segundo Tanguy (1991; 1999), estabelecer metodologicamente a genealogia das ideias e práticas daqueles que construíram políticas, estudos e pesquisas sobre estes campos de atividade: educação e trabalho.

Após minucioso trabalho de campo, Tanguy conclui que as representações sobre a formação como uma conquista social respondendo às necessidades dos trabalhadores e resultantes de acordo entre o patronato e o movimento sindical foram construções ideológicas. A formação, como direito, foi promovida pelos atores políticos como meio de controlar a luta política dos trabalhadores, isto é, de passar do movimento de confrontação à negociação.

A formação tem um lugar central na sociedade francesa e ocupa um lugar equivalente à educação. Diferentemente da educação escolar, que sempre foi uma política de Estado, a formação, embora induzida pelo Estado, é uma política de parcerias com o setor empresarial. De forma geral, o Estado tem perdido sua importância na organização, na gestão e no financiamento da formação para os "parceiros"; não nos esqueçamos que a noção de parceria oculta a assimetria de posições, de recursos e de poder. Assim, Tanguy conclui que a formação, na França, tem sido um laboratório de experimentações sociais e políticas.

Na França, segundo Tanguy, há uma riqueza de dados coletados que são analisados colocando em correspondência, sem questionar, a formação e o emprego, embora tenham como origem a crítica sobre a adequação entre modos de formação e as expectativas de "perfis" profissionais. Essas análises indicam uma compreensão de que o mercado de trabalho pode ser ajustado às políticas e à negociação entre diferentes atores sociais. As políticas que estabelecem relações entre trabalho e emprego apresentam-nas como necessárias, ainda que coloquem em oposição os dois fenômenos (Tanguy, 1986).

A articulação entre a formação e o emprego é instável e limitada. Para os trabalhadores, em especial para os jovens, o diploma não garante nem inserção 
profissional, nem segurança no trabalho, é uma condição necessária, mas não suficiente; e para os empregadores, os diplomas representam um recurso e uma restrição (Tanguy, 1986; Segnini, 2000). A lógica dos empregadores insiste sobre as carências e as insuficiências, o que permite, em períodos de crise, aumentar as exigências de formação. Ao mesmo tempo desencoraja os jovens a se inserirem no mercado de trabalho, incitando-os a continuarem seus estudos, pois a saída da escola se traduz por desemprego, estágios, empregos precários, entre outros. Assim, a relação entre formação e emprego é um constructo ideológico, ao propor funções de integração social, de legitimação e de dissimulação das contradições sociais que ocultam as mudanças sociais e econômicas (Tanguy, op. cit.).

As políticas educacionais na França, a partir dos anos de 1980, têm como característica incorporar o emprego como um de seus objetivos. As relações entre formação, qualificação e emprego transformaram a noção de educação e esta passou a assumir a concepção de qualificação. Este deslocamento oculta o fato de que a qualificação não é um atributo conferido pelo sistema educacional, mas uma relação social que combina escolarização, formação no/pelo trabalho com os atributos do posto de trabalho. A dinâmica do mercado de trabalho evidencia que qualificação não está associada aos diplomas, sendo ela, entre outros, um sistema de classificação. Neste sistema classificatório, um trabalhador é qualificado para ocupar um posto de trabalho se ele prova que possui as qualidades requeridas pelo mercado de trabalho. Da mesma forma, um trabalhador é considerado desqualificado se suas capacidades são desconhecidas ou não são valorizadas pelo mercado de trabalho. Portanto, a qualificação é um constructo social (Kergoat, 1986).

\section{Qualificação e competências}

A noção de qualificação se fundamenta num conjunto de práticas sociais que buscam colocar em correspondência os sistemas educativos e produtivos. Como prática social, coloca em relação dois fenômenos separados histórica e institucionalmente: o sistema de educação, que objetiva a formação de trabalhadores, e o sistema produtivo, que emprega os trabalhadores. A qualificação, portanto, se coloca no ajuste da escolaridade e do emprego e, nesta direção, é um sistema de classificação que estabelece as formas de recrutamento dos trabalhadores, a indicação para os postos de trabalho, os salários e as promoções.

A noção de qualificação emerge com uma das mais ambíguas e controvertidas na sociologia do trabalho, pois, de um lado, pretendia-se construir uma noção de qualificação apoiada na qualidade do trabalho e, de outro, pretendia-se avaliar as transformações da qualificação. A noção de qualificação, desde Naville (1956), é considerada uma relação social e, como tal, expressa relações de poder, tensões, 
conflitos. Desta forma, a noção de qualificação ora se refere ao posto de trabalho, ora ao trabalhador.

O questionamento da noção de qualificação é forjado em contextos de desemprego. O desenvolvimento tecnológico e a reestruturação das atividades produtivas impuseram não somente o desemprego, como também um processo de desqualificação de parte dos trabalhadores, e criaram um terreno fértil para germinar a noção de competências. Se esta noção emerge como capacidade de constante adaptação às mudanças no mundo do trabalho, ela também estabelece limites para a noção de qualificação.

As relações entre educação e trabalho se transmutam para as relações entre competências, educação e trabalho. O deslocamento do espaço ocupado pela qualificação para o de competência permite a disputa na instituição escolar da noção de formação; esta se apresenta com novos atributos, dentre os quais se destacam aqueles referentes à formação de indivíduos flexíveis e polivalentes. Nesta direção, o espaço ocupado na escola, outrora, pelos "saberes disciplinares" é substituído pelas competências verificáveis em situações específicas. Desta forma, observa-se que tanto nas organizações produtivas, como nas educacionais há uma centralidade nos atributos dos indivíduos, sejam eles alunos ou trabalhadores.

As competências na esfera educativa se constituem não somente como teoria do conhecimento, mas também como pedagogia e modo de avaliação. Assim, como teoria do conhecimento a ação e conhecimento são indissociáveis; como pedagogia, é um modo de transmissão de conhecimentos; como modo de avaliação, é uma lista de objetivos a serem verificados (estes objetivos são apresentados como capacidades de realização de tarefas em determinadas situações). A força desta noção é sua aparência científica, com dispositivos técnicos, referenciais, categorizações e classificações universais e mensuráveis. Apresenta-se como garantia de eficácia econômica (mediante avaliações nacionais), social (mediante a noção de equidade) e pedagógica (possibilita o controle de resultados). As competências, como modelo, apresentam duas faces: uma que padroniza objetivos, métodos e resultados contra a chamada pedagogia invisível (Bernstein, 1975) e as teorias da reprodução (Bourdieu \& Passeron, 1982; Bourdieu, 1998); a segunda se assenta numa racionalidade instrumental, que reduz os conhecimentos aos métodos e ao saber fazer (Tardif \& Lessard, 1999). É uma nova forma de regulação que permite a validação da experiência profissional e reconversão de carreiras, além de posicionar no mesmo patamar a escola, os diplomas e a validação de experiências. Desta forma, a noção de competência é emblemática nas transformações sociais nas esferas da educação e do trabalho.

Se a noção de competências emerge do estabelecimento de políticas de emprego orientadas pelas mudanças na organização e na gestão do trabalho, estas políticas, também, se inscrevem na contração dos empregos, nas mudanças tecnológicas, na 
concorrência dos mercados, no declínio da ação sindical, entre outros. Nas empresas a formação passa a ser definida em termos de competências, noção esta que é explicitada em três registros: saber (conhecimento), saber-fazer (habilidades) e saber-ser (comportamento); e definida por objetivos a serem atingidos. Assim, nas ações de reconversão profissional, a formação é concebida como atividade individualizada, construída por percursos ou trajetórias profissionais, decompostas de módulos que podem ser validados mediante a mensuração de "ser capaz de".

Embora Tanguy evidencie que a incorporação da noção de competências às políticas de educação, emprego e trabalho está associada às mudanças econômicas e políticas implementadas a partir do pós-guerra, na França, esse movimento não se restringe somente aos países centrais. No Brasil, com outras nuanças, a introdução da noção de competências está associada à reestruturação das atividades produtivas ${ }^{2}$ e às políticas de educação profissional, a partir dos anos de 1990. Foram inúmeras as iniciativas governamentais de mudanças na educação profissionais: Lei n. 9.394/1996 sobre as diretrizes e bases da educação nacional (LDB), Decreto n. 2.208/1997, que regulamentou a LDB quanto à educação profissional; a Portaria Ministerial n. 646, que organizou a rede federal de educação e o Programa de Expansão da Educação Federal (Proep). Segundo Moraes (2002), esse conjunto de mudanças estava inserido no projeto de modernização do país:

\footnotetext{
O uso indiferenciado das duas noções - educação e formação - (...) associa-se à avaliação negativa do "aparelho escolar formal" que "distante de um sistema produtivo em permanente e rápido processo de modernização" tem se mostrado "incapaz de atender com agilidade a crescente demanda por níveis mais elevados de qualificação" (...). A orientação conservadora da política educacional brasileira define como objetivo prioritário para o sistema educacional a produção da qualidade capaz de viabilizar o desenvolvimento de "competências para a produtividade". (Moraes, 2002, p. 2 e 4; grifo do original)
}

As mudanças, indicadas por Moraes (op. cit.), implicam a mobilização dos indivíduos, representados frequentemente em termos de carências, de privação de recursos necessários à realização das reformas preconizadas. Portanto, os destinatários da qualificação são considerados menos qualificados. A formação, nestes termos, é compreendida como uma obrigação e não um direito. No Brasil, como na França, os discursos governamentais constroem a noção de empregabilidade, indicando que o trabalhador é responsável por sua trajetória profissional; portanto, a formação e a educação não são mais projetos societários, mas projetos individuais.

\section{Trabalho e profissão}

Outra distinção importante para o debate sobre as fronteiras entre as esferas de duas atividades sociais é a retomada da sociologia das profissões pelos sociólogos 
franceses que estudam determinadas categorias de trabalhadores, em especial nas atividades de serviços. A análise sociológica das profissões é um campo com menor visibilidade na França, pois as noções de ocupação e profissão são similares e problemáticas nas análises sobre as relações de trabalho.

O distanciamento dos sociólogos franceses deve-se ao fato, entre outros, de que as profissões, na sociologia anglo-saxônica, constituem segmentos particulares, hierarquizados, uma elite de trabalhadores muito qualificados, com forte autonomia e independência para exercer suas atividades (Menger, 2003). A retomada, pela sociologia francesa, dos estudos das profissões as compreende como formas históricas não só de organização social, mas também como possibilidades de classificar as atividades de trabalho, pois colocam em evidência as relações sociais e, portanto, políticas (Dubar \& Tripier, 1998). As profissões significam formas históricas de exercício profissional, "de identificação subjetiva de seus membros, de expressão de valores de ordem ética, plena de significações culturais" (Segnini \& Souza, 2003, p. 9). Como relação social, as profissões expressam contradições, antagonismos e tensões entre atores sociais e instituições, que procuram assegurar espaços de formação profissional, no mercado de trabalho, de reconhecimento social mediante direitos sociais.

É nesta perspectiva que Tanguy (1991) retoma a noção de profissão, não com a preocupação de conhecer um grupo profissional que tem um lugar no mosaico socioprofissional, mas para analisar as práticas de transmissão de saberes e de socialização dos grupos profissionais. O estudo de Tanguy sobre os professores da educação profissional tem como foco a compreensão da morfologia e das identidades dos professores dos liceus profissionais, suas trajetórias, posições de classe, práticas e aprendizagem de uma profissão em constante renovação. Neste sentido, estabelece um estreito diálogo entre a sociologia do trabalho e das profissões nas análises sobre a organização social das atividades de trabalho, sua significação subjetiva e os modos de estruturação dos mercados de trabalho do campo da educação. Assim, as tensões que se estabelecem em torno das profissões expressam também as tensas relações entre educação e emprego.

Tomando os professores como referência, eles constituem uma categoria social que, assim como outras, é definida pela sua formação e pelo caráter do seu trabalho; eles são singulares pelo fato de que vivem (ou procuram viver) do trabalho que realizam. Compreender, sociologicamente, como se formam, como se organizam, como trabalham é, entre outros aspectos, romper com a noção de que trabalho, formação e profissão são dimensões sociais distintas.

A análise sociológica que Tanguy realiza sobre os professores não está dissociada, metodologicamente, das configurações históricas que organizam as relações de trabalho docente e da necessidade de dar visibilidade aos trabalhadores que, 
muitas vezes, são invisíveis ou não são ouvidos. Neste sentido, colocou os professores na cena, mais precisamente os professores da educação profissional, aqueles que se ocupam nos liceus profissionais da formação de operários e técnicos, os trabalhadores, compreendendo-os como categoria profissional composta por indivíduos com trajetórias escolares e profissionais singulares e diversas.

Os professores da educação profissional, na França, assim como no Brasil, são uma categoria profissional que se renova constantemente; as primeiras gerações de professores eram formadas por antigos operários e técnicos. Hoje, é do conhecimento de todos que eles desapareceram da cena escolar. $O$ recrutamento e a seleção de professores, no Brasil, deixaram de privilegiar, em parte, a inserção no setor produtivo para priorizar os títulos e diplomas universitários dos candidatos aos postos de professores em escolas técnicas (Souza, 2011).

A partir de pesquisa focada nos professores, como sujeitos históricos e suas práticas profissionais, é possível iluminar certo número de relações nas quais se inscrevem a educação profissional: o lugar no sistema educacional, as relações entre a organização do trabalho e as políticas públicas, entre outros. Desmistificar é uma tarefa das ciências sociais, difícil, pois as crenças resistem ao conhecimento dos fatos. Permite também romper com os discursos dominantes sobre a educação que postulam relações lineares entre mudanças tecnológicas, imperativos econômicos e novos modos de formação profissional, pois oferecem soluções simples a problemas sociais complexos. Há um encontro entre estes discursos e a ideologia que os sustenta. A análise das relações entre educação e trabalho indica como as demandas econômicas são traduzidas em termos de formação profissional. Neste sentido, há que compreender as significações dos termos que informam o debate aqui proposto.

\section{Considerações finais}

Não foi intenção deste artigo apresentar um estado da pesquisa sobre as relações entre trabalho e educação, as fronteiras ou suas ausências, a partir da obra de Lucie Tanguy, mas nomear o debate construído por esta socióloga em torno da sociologia que tem como objeto de estudos e pesquisas o trabalho e a educação. Trata-se de um texto com sentido mais interrogativo que afirmativo.

Nas análises sociológicas propostas por Tanguy constata-se a descoberta de uma variedade de formas e categorias de pesquisa, que nos permitem romper, primeiramente, com as fronteiras entre trabalho e profissões. A expansão das análises sobre o trabalho em diferentes esferas de atividades sociais permite compreender problemáticas encontradas nos professores, cientistas, artistas, cirurgiões, entre outros, cujas pesquisas são priorizadas pelos sociólogos que estudam profissões. Aos 
sociólogos são colocadas provocações intelectuais sobre como comparar o trabalho de carpinteiro com o de professor, superando as divisões entre especialidades de pesquisa, ou seja, entre profissões, ocupações ou trabalho.

Decorrente da superação da clivagem entre profissão e trabalho, a análise das diferentes esferas de atividades sociais se apresenta, relativamente, fecunda. Tomo como exemplo o trabalho docente, ao invés de procurar os atributos típicos das profissões daqueles que trabalham em instituições que oferecem serviços ao público. Tomo-os como trabalhadores, sem esquecer a dimensão deste trabalho, relativamente central, como "relação de serviço" que se desenvolve com o avanço do trabalho em serviços em diferentes contextos societários. A passagem de fronteiras envolve $o$ deslocamento de objetos de pesquisa, mas não do lugar de investigação, que continua sendo a sociologia.

A segunda ruptura de fronteiras aqui proposta é entre sociologia da educação e do trabalho com objetos de pesquisas - trabalho e educação - tratados, grosso modo, separadamente. Acompanhando o raciocínio sociológico de Tanguy, em primeiro lugar é preciso examinar e interrogar os nomes, as noções que se utiliza, pois elas contribuem para a constituição da realidade social. Depois, o tipo de análise sociológica que se produz sobre as esferas de atividades sociais contribuem para dar forma às representações e às políticas que buscam estabelecer relações entre formação/educação e emprego/trabalho. Essas representações e políticas apresentam as relações entre formação e emprego como necessárias, ainda que o propósito seja estabelecer oposições entre elas. A formação aparece, nas representações e políticas, como condição para o acesso ao emprego, ocultando as relações sociais que informam as relações entre diplomas e acesso ao mercado de trabalho; e com exceção das diferenças de gênero, as desigualdades sociais são apresentadas como desigualdades escolares. Adotar uma perspectiva analítica sociológica que recusa a autonomização das esferas de atividades sociais exige compreender as divergências e contradições que permite colocar em evidência a valorização exacerbada da educação para resolver os problemas do trabalho, e mais especificamente do emprego.

Concluo, repondo o problema que dá origem ao artigo: as mudanças mais significativas no sistema educacional brasileiro, nas últimas décadas, colocam o emprego no centro das políticas. Esta centralidade se traduz não somente em mudanças institucionais, mas também em modelos cognitivos e culturais difundidos pela escola. De forma geral, as pesquisas destes fenômenos são realizadas a partir de campos teóricos distintos, nos quais a sociologia tem, ainda, pouca presença. Esta especialização dos estudos, de um lado, testemunha a vitalidade da pesquisa; de outro, evidencia uma pluralidade de quadros teóricos e relativa ausência de sociólogos. Este debate não é novo: Luiz Antonio Cunha advertia (em seminário realizado à professora Aparecida Joly Gouveia, em 1991, na USP), sobre o fato de que 
"a educação é muito pouco valorizada como objeto de pesquisa e de especialização temática pelos sociólogos brasileiros". A atualidade da problemática evidencia a importância de Lucie Tanguy que, na melhor tradição científica francesa, busca construir uma sociologia que, ao recusar as clivagens analíticas das esferas de atividades sociais, permite que se interrogue como campo de conhecimento.

\section{Notas}

1. Este livro é parte do relatório da pesquisa desenvolvida junto com Catherine Agulhon e Arlete Poloni.

2. Reestruturação das atividades produtivas "fazia referência a um cardápio de mudanças sociais que afetavam os chamados "chãos da fábrica", neles alterando a forma tecnológica e organizacional de produzir, as estratégias de gerenciar as relações de trabalho, e de negociar o consentimento face dos novos padrões de produção, e atingindo o próprio perfil dos trabalhadores" (Guimaraes, 2004, p. 18).

\section{Referências}

BERNSTEIN, B. Class, codes and control. London: Routledge, 1975.

BOURDIEU, P. A escola conservadora: as desigualdades frente à escola e à cultura. In: NOGUEIRA, M.A; CATANI, A. (Org.). Pierre Bourdieu: escritos de educação. Petrópolis: Vozes, 1998.

BOURDIEU, P.; PASSERON, J-C. A reprodução: elementos para uma teoria do sistema de ensino. 2. ed. Rio de Janeiro: Francisco Alves, 1982.

BRUCY, G. et al. Former pour réformer: retour sur la formation permanente (19452004). Paris: La Découverte, 2007.

CACOUAUlT, M.; OEUVRARD, F. Sociologie de l'éducation. Paris: La Découverte, 1995.

DEMAILLY, L. La qualification ou la compétence professionnelle des enseigants. Sociologie du Travail, Paris, v. 29, n. 1, p. 59-69, 1987.

DUBAR, C.; TRIPIER, P. Sociologie des professions. Paris: Armand Colin, 1998.

FERNANDES, F. Ensaios de sociologia geral e aplicada. São Paulo: Pioneira, 1960.

FRIEDMANN, G.; NAVILLE, P. Tratado de sociologia do trabalho. São Paulo: Cultrix; EDUSP, 1973.

GAUDIN, J.- P. Gouverner par contrat, l'action publique en question. Paris: FNSP, 1999.

GUIMARÃES, N.A. Caminhos cruzados. São Paulo: Editora 34, 2004. 
JOBERT, A.; MARRY, C.; TANGUY, L. Éducation et travail en Grande Bretagne, Allemagne et Italie. Paris: Armand Colin, 1995

KERGOAT, D. Em defesa da sociologia das relações sociais: da análise crítica das categorias dominantes à elaboração de uma nova conceituação. In: KARTCHEVSKYBULPORT, A. et al. O sexo do trabalho. Rio de Janeiro: Paz \& Terra, 1986. p. 69-94.

MENGER, P-M. (Org.). Les professions et leurs sociologues. Paris: MSH, 2003.

MORAES, C.S.V. Educação, trabalho e formação profissional. In: PRADO, M.L.C; VIDAL, D.G. (Org.). A margem dos 500 anos: reflexões irreverentes. São Paulo: Edusp, 2002.

NAVILLE, P. Essai sur le qualification du travail. Paris: Marcel Rivière, 1956.

RAMOS, M.N. A pedagogia das competências e a psicologização das questões sociais. Boletim Técnico do Senac, Rio de Janeiro, v.27, n. 3, p. 26-35, set./dez. 2001.

ROPÉ, F.; TANGUY, L. Le modele des compétences: système éducatif et entreprise. L'Année Sociologique, Paris, v. 50, n. 2, p. 493-519, 2000.

ROPÉ, F.; TANGUY, L. (Org.). Saberes e competências: o uso de tais noções na empresa e na escola. Campinas: Papirus, 2001.

SEGNINI, L. Educação e trabalho: uma relação tão necessária quanto insuficiente. São Paulo em Perspectiva, São Paulo, v. 14, n. 2, p. 72-81, abr./jun. 2000.

SEGNINI, L.; SOUZA, A.N. Trabalho e formação profissional no campo da cultura: professores, bailarinos e músicos. São Paulo: Fapesp, 2003. (Projeto de pesquisa).

SOUZA, A.N. Mercado de trabalho e modos de vida: professores face às formas de desestabilização de direitos. Brasília, DF: CNPq, 2011. (Relatório de pesquisa).

TANGUY, L. L'introuvable relation formation/emploi: un état de recherches en France. Paris: La Documentation Française, 1986.

TANGUY, L. L'enseignement professionnel em France: des ouvriers aux techniciens. Paris: PUF, 1991.

TANGUY, L. Regards sur l'éducation: introduction. Sociétés Contemporaines, Paris, n. 11/12, p. 5-11, sept./déc. 1992.

TANGUY, L. La formation, une activité en voie de définition? In: COSTER, M.; PICHAUT, F. (Org.). Traité de sociologie du travail. Bruxelles: De Boeck, 1994.

TANGUY, L. Do sistema educativo ao emprego. Formação. Um bem universal? Educação \& Sociedade, Campinas, v. 20, n. 67, p. 48-69, ago. 1999. 
TANGUY, L. Histoire et sociologie de l'enseignement technique et professionnel em France: um siècle em perspective. Note de synthése. Revue Française de Pédagogie, Paris, n. 131, p. 97-127, avr./juin. 2000.

TANGUY, L. De la evaluation de los puestos de trabajo a las cualidades de los trabajadores; definiciones y usos de la noción de competências. In: TOLEDO, E.G.; NEFFA, J.C. (Coord.). El futuro del trabajo. Buenos Aires: Flacso, 2001. p. 111-128.

TANGUY, L. Um movimento social para a formação permanente na França, 19451970. Pro-Posições, Campinas, v. 13, n. 37, p. 18-33, jan./abr. 2002.

TANGUY, L. Les instituts du travail: la formation syndicale à l'université de 1955 à nos jours. Rennes: PUR, 2006.

TARDIF, M.; LESSARD, C. Le travail enseignant au quotidien: expérience, interactions humaines e dilemmes professionnels. Bruxelles: De Boeck, 1999.

Recebido em 26 de janeiro de 2012.

Aprovado em 4 de abril de 2012. 